\title{
Theory of vapor phase nucleation in binary mixtures of water and sulfuric acid.
}

\author{
W. J. Shugard \\ Richard H. Heist \\ Fairfield University, rheist@fairfield.edu
}

Follow this and additional works at: https://digitalcommons.fairfield.edu/engineering-facultypubs

(C) 1975 American Institute of Physics.

The final publisher PDF has been archived here with permission from the copyright holder. https://aip.scitation.org/doi/abs/10.1063/1.1681879

\section{Peer Reviewed}

\section{Repository Citation}

Shugard, W. J. and Heist, Richard H., "Theory of vapor phase nucleation in binary mixtures of water and sulfuric acid." (1974). Engineering Faculty Publications. 157.

https://digitalcommons.fairfield.edu/engineering-facultypubs/157

\section{Published Citation}

Shugard, W. J., Heist, R. H., \& Reiss, H. (1974). Theory of vapor phase nucleation in binary mixtures of water and sulfuric acid. The Journal of Chemical Physics, 61(12), 5298-5304. doi:10.1063/1.1681879.

This item has been accepted for inclusion in DigitalCommons@Fairfield by an authorized administrator of DigitalCommons@Fairfield. It is brought to you by DigitalCommons@Fairfield with permission from the rightsholder(s) and is protected by copyright and/or related rights. You are free to use this item in any way that is permitted by the copyright and related rights legislation that applies to your use. For other uses, you need to obtain permission from the rights-holder(s) directly, unless additional rights are indicated by a Creative Commons license in the record and/or on the work itself. For more information, please contact digitalcommons@fairfield.edu. 


\title{
Theory of vapor phase nucleation in binary mixtures of water and sulfuric acid*
}

\author{
W. J. Shugard, R. H. Heist, and H. Reiss \\ Department of Chemistry, University of California, Los Angeles, California 90024 \\ (Received 27 June 1974)
}

\begin{abstract}
An expression for the nucleation rate of a binary vapor mixture of $\mathrm{H}_{2} \mathrm{O}$ and $\mathrm{H}_{2} \mathrm{SO}_{4}$ at $25^{\circ} \mathrm{C}$ is derived which explicitly considers the contribution of $\mathrm{H}_{2} \mathrm{SO}_{4}$ hydrates to the droplet growth process. The continuum approximation used in earlier binary rate treatments has been abandoned in favor of treating the droplet composition in a discrete fashion. Rates of nucleation are calculated for a $\mathrm{H}_{2} \mathrm{O}-\mathrm{H}_{2} \mathrm{SO}_{4}$ vapor mixture at $50 \%, 200 \%$, and $300 \%$ relative humidities for various $\mathrm{H}_{2} \mathrm{SO}_{4}$ vapor activities. A finite nucleation rate is predicted with a relative humidity of $50 \%$ and a monomer $\mathrm{H}_{2} \mathrm{SO}_{4}$ vapor activity of $10^{-3}$. This translates to a vapor pressure of monomer $\mathrm{H}_{2} \mathrm{SO}_{4}$ of $3.6 \times 10^{-7}$ $\mathrm{mm} \mathrm{Hg}$ or $0.5 \mathrm{ppb}$ of pure $\mathrm{H}_{2} \mathrm{SO}_{4}$ at $1 \mathrm{~atm}$. At higher relative humidities (i.e., 300\%), a finite nucleation rate is predicted for monomer $\mathrm{H}_{2} \mathrm{SO}_{4}$ concentrations of $\sim 0.04$ ppt. This represents a vapor pressure of $3.2 \times 10^{-11} \mathrm{~mm} \mathrm{Hg}$ for monomer $\mathrm{H}_{2} \mathrm{SO}_{4}$.
\end{abstract}

\section{INTRODUCTION}

The role of sulfuric acid in aerosol formation in moist air is a subject of increasing environmental interest. The current state of this field is summarized conveniently by Bricard et al. ${ }^{1}$ Almost no truly quantitative understanding of the problem exists, although a wealth of reliable qualitative results is available. This situation in no way results from the inadequacy of investigators, but rather from the surprising complexity of the systems involved, the difficulty of establishing instrumental methods for observing individual events at levels approaching the molecular, and, when the atmosphere itself is concerned, the impossibility of accurately reproducing environmental conditions in the laboratory.

With so much effort focused on atmospheric pollution, it is natural to attempt a phenomenological understanding of the integrated system before concentrating research on its component parts. Thus, work in smog chambers, flow chambers, and cloud chambers, has been aimed more at producing complicated "smogs" and "clouds" than at generating chemical precursors for, and the production of, single aerosol particles. Chemical reactions, photolysis, radiolysis, nucleation, and growth are but a few of the processes that must be dealt with, and a synthesis, based on a study in which all are occurring simultaneously, has its limits in providing a firm understanding of individual mechanisms.

Despite the focus on the "whole" system, the last decade has seen definite progress in the examination of component processes under relatively well controlled conditions. Most of this progress has occurred in the fields of reaction kinetics and photochemistry, where it has become feasible to measure the rate constants for elementary reaction steps without interference from smog chamber walls, using fluorescence excitation techniques. ${ }^{2}$ Considerable progress has also been made in the study of primary photochemical processes, for example in the photooxidation of $\mathrm{SO}_{2 .}{ }^{3,4} \mathrm{As}$ data on elementary rate constants have been accumulated, the computer has been used ${ }^{5,6}$ to exploit models based on large numbers of simultaneous differential rate equations, and methods have been developed for handling "stiff" equations.

In addition, the molecular beam has been brought in play in order to study complex formation, ${ }^{8}$ condensation, ${ }^{9}$ and other elementary events connected, possibly with aerosol formation.

A particularly promising tool appears to be the clou chamber, which has been used in three variations, namely the expansion chamber, ${ }^{10}$ the flow diffusion chamber, ${ }^{11}$ and the static diffusion chamber. ${ }^{12,13}$ In the first two modes, the emphasis seems, again, to have been on producing whole clouds under rather con plicated conditions, followed by the use of light scatter ing and theory in an attempt to unfold the data. The flow diffusion chamber has the advantage of permitting the addition of nucleating agents of known composition and size distribution to the condensing medium, but th control can be good only at moderate supersaturation $(<1.5)$, since at higher supersaturation it must be almost impossible to filter out nucleating centers so as to provide a nucleus-free standard state to which know nucleating agents can be added.

The static diffusion chamber has been employed mai ly in the study of homogeneous nucleation, ${ }^{12-14}$ in unary or one-component systems, and also in the study of condensation on ions, ${ }^{15}$ not to mention its original application in high energy physics. During the 1960's, $K{ }^{2} z^{12}$ refined it into a very effective tool for this purpose. The present authors are currently engaged in at attempt to apply it to a wider range of problems in physical chemistry, among them the study of the photo oxidation of $\mathrm{SO}_{2}$ and the mechanism of nucleation in binary mixtures of water and sulfuric acid. Our preliminary observations, coupled with a theory of hydrat formation published recently, ${ }^{16}$ suggest the appropriate mechanism for the nucleation of droplets in sulfuric acid-water mixtures. An early calculation indicates that $\mathrm{H}_{2} \mathrm{SO}_{4}$ at partial pressures as low as $10^{-9}-10^{-8} \mathrm{~m}$ $\mathrm{Hg}$ or less than $1 \mathrm{ppt}$ (a probable atmospheric concentration), ${ }^{11}$ is capable of nucleating air at $50 \%$ relative humidity. This conclusion was arrived at by Doyle ${ }^{17}$ on the basis of another mechanism related to a general theory of binary nucleation published earlier. ${ }^{18}$ 
Mirabel and Katz ${ }^{19}$ refined Doyle's calculation and, on the basis of a more realistic estimate ${ }^{20}$ of the vapor pressure of pure sulfuric acid, decided that pressures in the range $10^{-7}-10^{-6} \mathrm{~mm} \mathrm{Hg}$ would be required. The mechanism described below also predicts nucleation in this higher range of partial pressure still typical of some atmospheric condition.

This is a very important conclusion, since considerable controversy exists ${ }^{1}$ over whether $\mathrm{H}_{2} \mathrm{SO}_{4}$ at atmospheric concentrations can be the precursor to aerosol formation.

\section{THEORY}

In view of the general importance of the problem, and in preparation for the analysis of experimental data obtained in connection with our cloud chamber studies (to be reported in a later paper) on the photo-oxidation of $\mathrm{SO}_{2}$, we develop, in this paper, what we now feel to be a more adequate, even if not perfect, theory of nucleation for $\mathrm{H}_{2} \mathrm{SO}_{4}-\mathrm{H}_{2} \mathrm{O}$ mixtures.

The mechanism of nucleation, treated in Refs. 17-19, took no account of hydrate formation as described in Ref. 16. A good place to begin the exploration of the possible effects of hydrates is Fig. 8 of Ref. 16, which we reproduce here as Fig. 1. The surface depicted in Fig. 1 is a computer-generated three-dimensional perspective plot representing the reversible work $W$ required to form a liquid drop containing $n_{1}$ molecules of $\mathrm{H}_{2} \mathrm{O}$ and $n_{2}$ molecules of $\mathrm{H}_{2} \mathrm{SO}_{4}$ from an initially homogeneous vapor. The plot is drawn in such a manner that the viewer appears to be looking down on the surface at a polar angle $\psi$ of $45^{\circ}$ from the vertical axis, and an azimuthal angle $\xi$ about this axis of $315^{\circ}$. The perspective corresponds to the observer being at a distance $d$ four body diagonals away from the origin. These values of $\psi, \xi$, and $d$ give the viewer the impression that he is sitting behind and above the origin, looking over the surface out into "left field." This surface corresponds to a temperature of $25^{\circ} \mathrm{C}$, and to a relative humidity of $300 \%$ with acid $\left(\mathrm{H}_{2} \mathrm{SO}_{4}\right)$ activity in the vapor of $10^{-3}$. Such an acid activity translates into a partial pressure of $\mathrm{H}_{2} \mathrm{SO}_{4}$ equal to $3.6 \times 10^{-7} \mathrm{~mm} \mathrm{Hg}$. The saddle point on the free energy surface in Fig. 1 occurs (according to Table I of Ref. 16) when the drop contains 1.66 molecules of $\mathrm{H}_{2} \mathrm{SO}_{4}$ and 6.93 molecules of $\mathrm{H}_{2} \mathrm{O}$. Once the saddle is reached, it is possible for the drop to increase in size by a process involving a decrease of free energy. However, that process may involve the addition of acid as well as water molecules!

For the particular conditions of Fig. 1 we show, in Fig. 2, the profile through the free energy surface along the grid corresponding to four acid molecules. i.e., the free energy of formation of a drop which always contains four acid molecules, and to which only water molecules are added as we move to the right, parallel to the water axis. We see from Fig. 2 that, as long as there are four acid molecules in the drop, the addition of water is always a downhill process. In this case, the drop can grow spontaneously through the addition of water molecules alone, provided no acid molecules are lost!
We can estimate the rate at which acid molecules are lost (or at least an upper limit to that rate) by considering the acid vapor pressure from the drop whose composition corresponds to the saddle point. This drop is in unstable equilibrium with its surroundings such that its acid vapor pressure is exactly $3.6 \times 10^{-7} \mathrm{~mm} \mathrm{Hg}$. According to Table I of Ref. 16, the radius of this drop is $R=5.594 \times 10^{-8} \mathrm{~cm}$, and therefore its surface area $4 \pi R^{2}$ is $3.932 \times 10^{-14} \mathrm{~cm}^{2}$. The rate (according to simple Maxwellian kinetic theory) at which gas molecules hit one square centimeter of plane surface is ${ }^{21}$

$$
\varphi=p / \sqrt{2 \pi m k_{B} T},
$$

where $p$ is the pressure, $m$ the molecular mass $k_{B}$ the Boltzmann constant, and $T$ the temperature. Therefore the rate at which the drop at the saddle is hit (regarding its surface as plane) is $\varphi 4 \pi R^{2}$. If the reflection coefficient (sticking coefficient) is assumed to be unity, this is also the rate of evaporation. Setting $4 \pi R^{2}=3.932 \times 10^{-14} \mathrm{~cm}^{2}, p=3.6 \times 10^{-7} \mathrm{~mm} \mathrm{Hg}, T=298^{\circ} \mathrm{K}$ or $25^{\circ} \mathrm{C}$, and $m=1.6 \times 10^{-22} \mathrm{~g}$ for $\mathrm{H}_{2} \mathrm{SO}_{4}$, we get $\varphi 4 \pi R^{2}$ $=2.9 \mathrm{sec}^{-1}$. Thus, on the average, $0.34 \mathrm{sec}$ elapses before a molecule of $\mathrm{H}_{2} \mathrm{SO}_{4}$ evaporates from or collides with the drop. Making the same calculation for water at $300 \% \mathrm{RH}$ shows that the corresponding time is only $7.53 \times 10^{-10} \mathrm{sec}$. Thus, the drop interacts with $\sim 10^{9}$

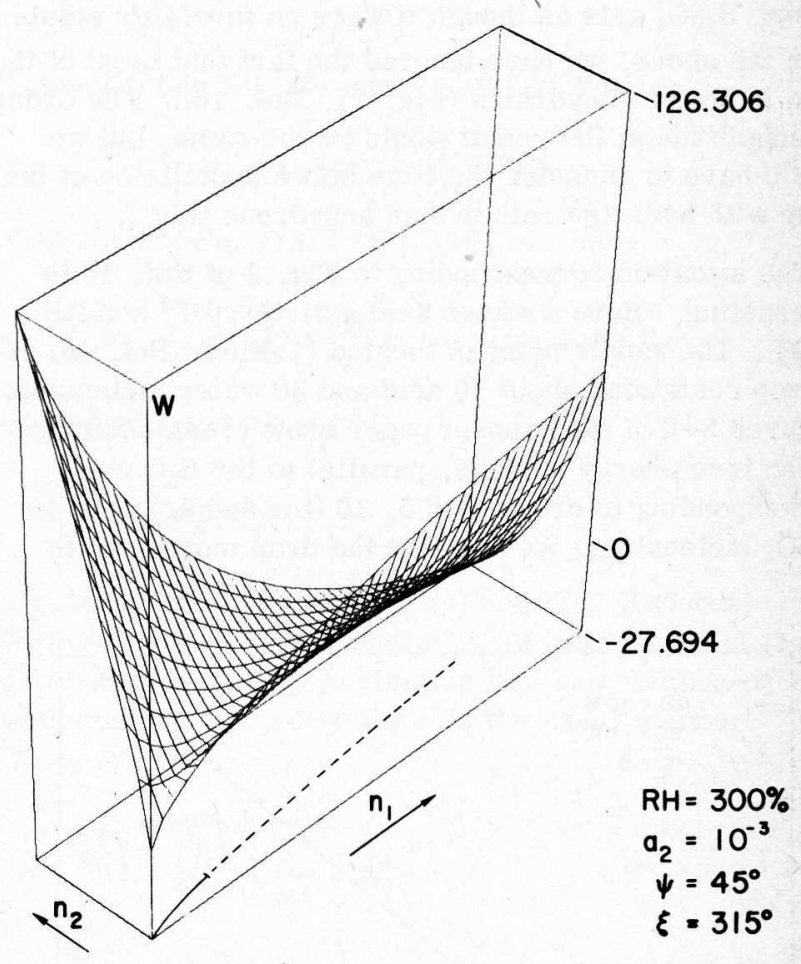

FIG. 1. The free energy surface for $\mathrm{H}_{2} \mathrm{O}-\mathrm{H}_{2} \mathrm{SO}_{4}$ droplet formation at $25^{\circ} \mathrm{C}$ with $\mathrm{RH}=300 \%$ and $a_{2}=10^{-3} . n_{1}$, the number of $\mathrm{H}_{2} \mathrm{O}$ molecules, and $n_{2}$, the number of $\mathrm{H}_{2} \mathrm{SO}_{4}$ molecules, range from 0 to 40 and 0 to 10 , respectively, and increase in the direction indicated by the arrows. The maximum and minimum values of the free energy $W$ are given on the plot. All the scales shown are linear. The projection of the path of minimum free energy through the saddle point is shown on the cube base. The ending of the solid line represents the saddle point. The viewing angles are $\psi=45^{\circ}$ down from the $W$ axis and $\xi=315^{\circ}$ about the $W$ axis. 


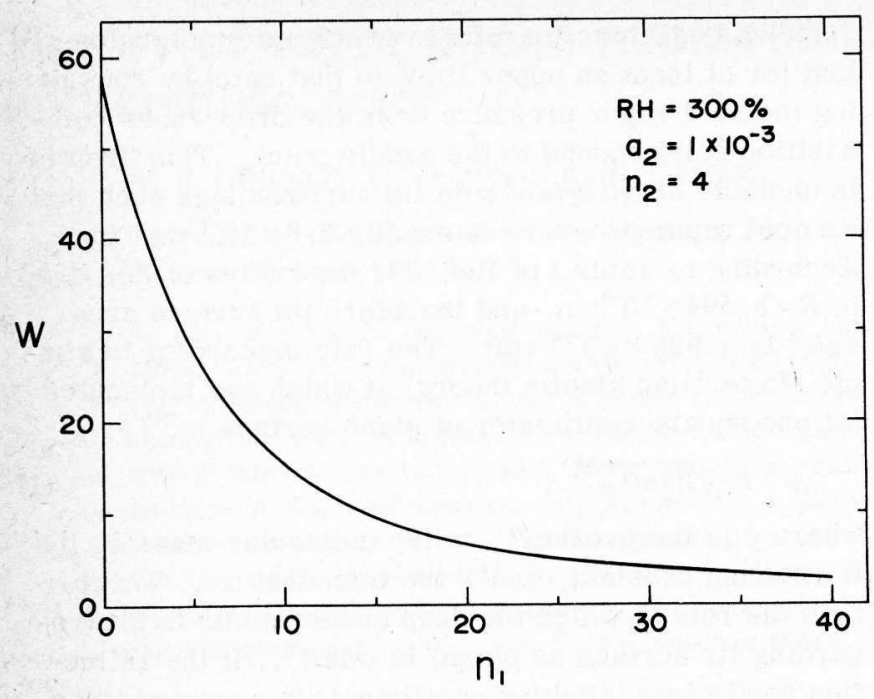

FIG. 2. A two-dimensional profile from the surface in Fig. 1 with $\mathrm{RH}=300 \%$ and $a_{2}=10^{-3}$. The profile shows the free energy $W$ of droplet formation for $4 \mathrm{H}_{2} \mathrm{SO}_{4}$ molecules and up to $40 \mathrm{H}_{2} \mathrm{O}$ molecules.

$\mathrm{H}_{2} \mathrm{O}$ molecules in the time between interactions with $\mathrm{H}_{2} \mathrm{SO}_{4}$ molecules. It may therefore always be regarded as being at equilibrium with respect to exchange with water molecules. Between exchanges with $\mathrm{H}_{2} \mathrm{SO}_{4}$ molecules, $\mathrm{H}_{2} \mathrm{SO}_{4}$ acts as though it were an involatile solute.

In the above, we have ignored the fact that most of the acid is bound in hydrates (Fig. 11, Ref. 16). The order of magnitude of the result would be the same, but we would have to consider the time between collision of the drop with hydrates rather than anhydrous $\mathrm{H}_{2} \mathrm{SO}_{4}$.

The situation corresponding to Fig. 2 of Ref. 16 is interesting. Here we have acid activity $=10^{-3}$ and $\mathrm{RH}$ $=50 \%$. The saddle point is located (Table I, Ref. 16) at a drop containing about 10 acid and 30 water molecules. Figures 3-5 of the present paper show cross sections of the free energy surface, parallel to the $\mathrm{H}_{2} \mathrm{O}$ axis, corresponding to drops with 5,10 (the saddle), and 12 $\mathrm{H}_{2} \mathrm{SO}_{4}$ molecules. We see that the drop moves up (in

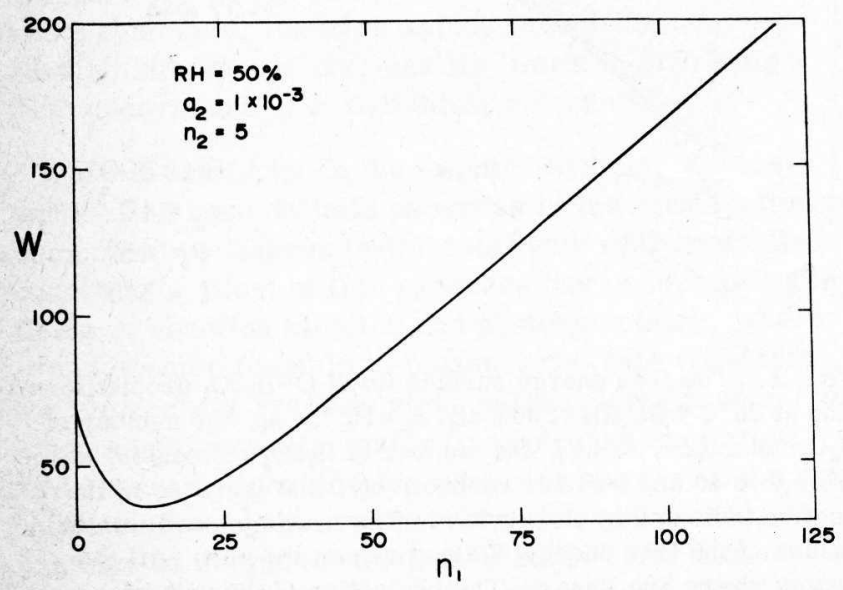

FIG. 3. A two-dimensional plot of the free energy $W$ of droplet formation for $5 \mathrm{H}_{2} \mathrm{SO}_{4}$ and up to $240 \mathrm{H}_{2} \mathrm{O}$ molecules at $25^{\circ} \mathrm{C}$ with $\mathrm{RH}=50 \%$ and $a_{2}=10^{-3}$.

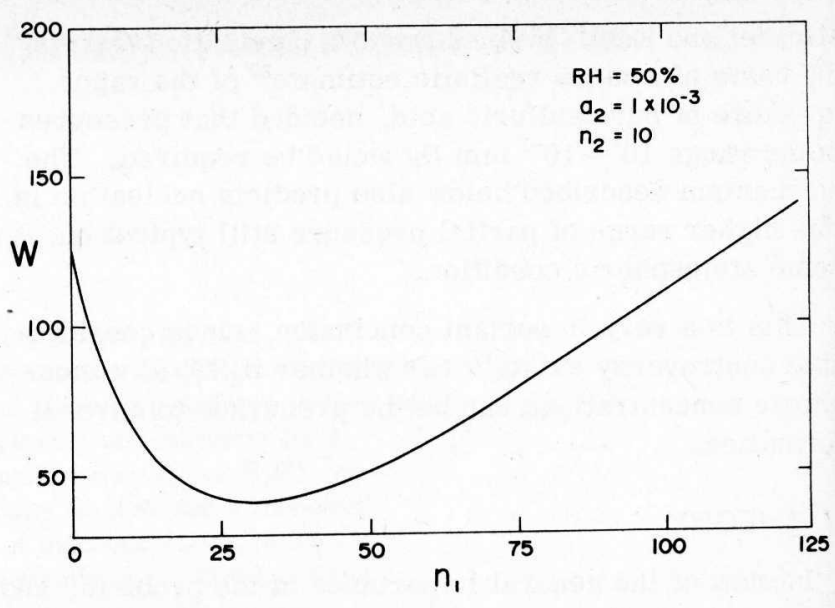

FIG. 4. A two-dimensional plot of the free energy $W$ of droplet formation for $10 \mathrm{H}_{2} \mathrm{SO}_{4}$ and up to $240 \mathrm{H}_{2} \mathrm{O}$ molecules at $25^{\circ} \mathrm{C}$ with $\mathrm{RH}=\mathbf{5 0} \%$ and $a_{2}=10^{-3}$.

the direction of increasing $\mathrm{H}_{2} \mathrm{SO}_{4}$ ) an increasingly broad valley. The valley can never vanish, no matter how broad it becomes, because the system is undersaturated both with respect to pure liquid water and pure acid. However, by adding acid molecules, larger drops can form, and once beyond the saddle, they are stable.

Doyle $\mathrm{e}^{17}$ conjectured over this possibility and suggested that in the atmosphere, very small traces of $\mathrm{H}_{2} \mathrm{SO}_{4}$ would lead to the formation of submicroscopic drops of $\mathrm{H}_{2} \mathrm{SO}_{4}$ solution which, although beyond the saddle, would cease to grow because the acid supply would become exhausted. However, such particulates could serve as condensation centers for other vapors, e.g., olefins. In order for this situation to arise, however, finite rates of nucleation are required. Whether high enough rates occur at low values of $\mathrm{RH}$ and small partial pressures of acid is a quantitative matter which can only be resolved by a definitive experiment or a reliable theoretical analysis.

Our experiments thus far indicate that finite rates occur at RH values in excess of $100 \%$ and at quite small

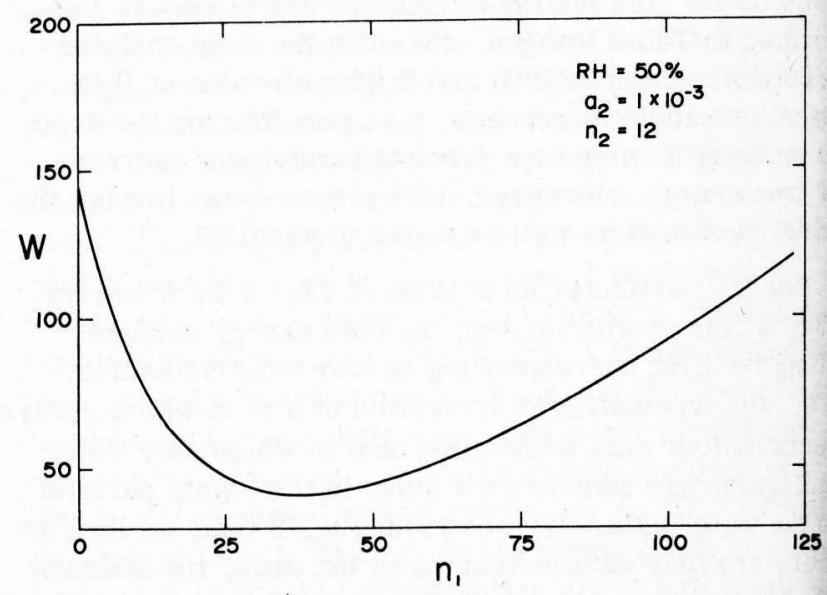

FIG. 5. A two-dimensional plot of the free energy $W$ of drople formation for $12 \mathrm{H}_{2} \mathrm{SO}_{4}$ and up to $240 \mathrm{H}_{2} \mathrm{O}$ molecules at $25^{\circ} \mathrm{C}$ with $\mathrm{RH}=50 \%$ and $a_{2}=10^{-3}$. 
concentrations of acid. They also occur at higher acid concentration and $\mathrm{RH}$ values less than $100 \%$. The aerosol, described by Doyle, is difficult but probably not impossible to observe (if it occurs). However, it will require equipment designed especially for this purpose.

We can develop the theory, confirm it for $\mathrm{RH}>100 \%$, and use it for prediction at $\mathrm{RH}<100 \%$. Both Doyle $\mathrm{e}^{17}$ and Mirabel and $\mathrm{Katz}^{19}$ have done this, ignoring hydrates, and using a continuum theory. ${ }^{18}$ Some modification is necessary when hydrates are present. Furthermore, at large values of $\mathrm{RH}$, the saddle occurs at such small drop sizes that it is reasonable to take the discrete nature of drop composition into account. We now do this.

The symbol $(i, j)$ indicates a drop composed of $i$ water and $j$ acid molecules. We then consider the following reactions around a "node" $(i, j)$ :

$$
\begin{gathered}
(i, j+1) \\
J_{i, j} \downarrow \uparrow \\
(i-1, j) \underset{I_{i-1, j}}{\longrightarrow}(i, j) \stackrel{I_{i, j}}{\longrightarrow}(i+1, j) . \\
\Downarrow J_{i, j-1} \\
(i, j-1)
\end{gathered}
$$

In these reactions, we have used the symbol $I$ to indicate net rates per $\mathrm{cm}^{3}$ at which water molecules are added, and $J$ for the net rates of acid addition. Net fluxes are positive to the right. In the steady state,

$$
I_{i-1, j}+J_{i, j-1}=I_{i, j}+J_{i, j} \text {. }
$$

From simple kinetic theory, ${ }^{21}$ the net rate at which acid hydrates strike a drop $(i, j)$ is

$$
\nu_{i, j}=(8 \pi k T)^{1 / 2} \sum_{h} \sigma_{h}^{2} \mu_{h}^{-1 / 2} N_{h},
$$

where $\sigma_{h}$ is the sum of the drop radius $R_{i, j}$ and the hydrate radius $R_{h}, \mu_{h}$ is the reduced mass of the drop $i, j$ and a hydrate with the $h \mathrm{H}_{2} \mathrm{O}$ molecules, and $N_{h}$ is the number of hydrates with $h \mathrm{H}_{2} \mathrm{O}$ molecules per $\mathrm{cm}$. The sum in Eq. (4) goes over all hydrate species. If we assume a sticking coefficient of unity, we may write

$$
J_{i, j}=\nu_{i, j} f_{i, j}-\gamma_{i, j+1} f_{i, j+1},
$$

where $\gamma_{i, j+1}$ is the rate of evaporation of $\mathrm{H}_{2} \mathrm{SO}_{4}$ from a drop $(i, j+1)$, and $f_{i, j}$ and $f_{i, j+1}$ are the concentrations of drops $(i, j)$ and $(i, j+1)$, respectively.

Applying detailed balancing in the usual manner, ${ }^{22}$ $\gamma_{i, j+1}$ can be eliminated, and we obtain

$$
J_{i, j}=\nu_{i, j} N_{i, j}\left(\frac{f_{i, j}}{N_{i, j}}-\frac{f_{i, j+1}}{N_{i, j+1}}\right),
$$

where $N_{i, j}$ and $N_{i, j+1}$ are the equilibrium concentrations of drops. We have [Eq. (18), Ref. 16]

$$
N_{i, j}=N\left[1-\left(\theta / N_{a}\right)\right] e^{-W_{i, j} / k T},
$$

where $N$ is the concentration of water molecules in the vapor and $N_{a}$ is the total concentration of acid molecules in and outside of hydrates. $W_{i, j}$ is the height on the free energy surface, e.g., Fig. 2 , at the point $(i, j)$. Finally,

$$
\theta=\sum_{h} N_{h},
$$

where the sum goes over all hydrates. In fact $N_{h}$ can be derived from Eq. (7) with $j=1$. Thus, $N_{h}=N_{h, 1}$.

Because of valley walls $I_{i, j}$ eventually goes to zero for small enough and large enough values of $i$. This means that in the steady state,

$$
J_{j}=\sum_{i} J_{i, j}=\sum_{i} J_{i, j+1}=J_{j+1}=J,
$$

where the definitions of $J_{j}$ and $J_{j+1}$ are obvious. Furthermore, if there is always local equilibrium as discussed above, with respect to the addition of water molecules, it follows that

$$
I_{i, j}=0 \text { and } \frac{f_{i, j}}{f_{s, j}}=\frac{N_{i, j}}{N_{s, j}},
$$

although, in general, $f_{i, j} \neq N_{i, j}$. We further define

$$
\begin{aligned}
f_{j} & =\sum_{i} f_{i, j} \\
\text { and } & \text { r } \\
N_{j} & =\sum_{i} N_{i, j}
\end{aligned}
$$

and from Eq. (10) we thus have

$$
\frac{f_{i, j}}{f_{j}}=\frac{N_{i, j}}{N_{j}} \text {. }
$$

Substituting Eq. (6) into Eq. (9) we get

$$
J=J_{j}=\sum_{i} \nu_{i, j} N_{i, j}\left(\frac{f_{i, j}}{N_{i, j}}-\frac{f_{i, j+1}}{N_{i, j+1}}\right) .
$$

Then, using Eq. (13) in Eq. (14), we have

$J=\left(\sum_{i} \nu_{i, j} N_{i, j}\right)\left(\frac{f_{j}}{N_{j}}-\frac{f_{j+1}}{N_{j+1}}\right)=\nu_{j} N_{j}\left(\frac{f_{j}}{N_{j}}-\frac{f_{j+1}}{N_{j+1}}\right)$,

where we have defined

$$
\nu_{j} N_{j}=\sum_{i} \nu_{i, j} N_{i, j},
$$

a quantity known from Eqs. (4) and (7). Equation (15), with $J$ constant independent of $j$, is in the form of the usual expression for nucleation in a one component system, and one can solve for $J$ in the usual manner. ${ }^{23}$ Thus, we get

$$
J=\left(\frac{f_{1}}{N_{1}}-\frac{f_{l}}{N_{l}}\right) /\left(\sum_{j=1}^{j=l-1} \frac{1}{\nu_{j} N_{j}}\right) .
$$

As usual, $f_{1} / N_{1}$ is negligibly different from unity, and if $l$ is chosen large enough, $f_{l} / N_{l}$ may be taken as zero. This gives

$$
J=\left(\sum_{j=1}^{j=i-1} \frac{1}{\nu_{j} N_{j}}\right)^{-1}
$$

for the rate of nucleation, in droplets $/ \mathrm{cm}^{3} \mathrm{sec}$.

In the next section we calculate values for $J$ for various conditions of acid activity and $\mathrm{RH}$. In particular we 
discover, like Doyle ${ }^{17}$ and Mirabel and Katz, ${ }^{19}$ that even in undersaturated ( $\mathrm{RH}$ as low as $50 \%$ ) air and with very low partial pressures of $\mathrm{H}_{2} \mathrm{SO}_{4}$, finite rates of nucleation are predicted. However, our theory accounts explicitly for hydrate formation and the noncontinuous nature of drop formation.

\section{NUMERICAL RESULTS}

To calculate the nucleation rate from the expressions in the preceding section, one needs first to calculate the free energy of formation of a cluster of $\mathrm{H}_{2} \mathrm{O}$ and $\mathrm{H}_{2} \mathrm{SO}_{4}$ molecules. The free energy $\mathrm{W}$ can be written as

$$
W=n_{1}\left(\mu_{1}-\vartheta_{1}\right)+n_{2}\left(\mu_{2}-\vartheta_{2}\right)+4 \pi r^{2} \sigma,
$$

where we have now assumed the liquid drop model. In Eq. (19), $\mu_{1}$ and $\mu_{2}$ represent the chemical potentials per molecule for $\mathrm{H}_{2} \mathrm{O}$ and $\mathrm{H}_{2} \mathrm{SO}_{4}$, respectively, taken in the bulk liquid phase; $\varphi_{1}$ and $\varphi_{2}$ represent the chemical potentials per molecule in the vapor; $r$ is the radius of the drop; and $\sigma$ is the surface tension, also taken for bulk solution. In Eq. (19), $\mathrm{H}_{2} \mathrm{SO}_{4}$ and $\mathrm{H}_{2} \mathrm{O}$ are chosen as the independently variable components. The standard states are pure $\mathrm{H}_{2} \mathrm{SO}_{4}$ and pure $\mathrm{H}_{2} \mathrm{O}$. These states are consistent with the thermodynamic data available, and are used to compute the free energy of the drop. Partial molar free energies were obtained from the bulk solution data of Giauque et al. $;^{24}$ partial molar volumes used to compute the drop radius were derived from bulk solution density measurements tabulated in the Chemical Engineers $\mathrm{Handbook}^{25}$; and the data for the surface tensions of $\mathrm{H}_{2} \mathrm{O}-\mathrm{H}_{2} \mathrm{SO}_{4}$ solutions have been published by Sabinina and Terpugaw. ${ }^{26}$ To allow interpolation, these data have been fitted to a variety of polynomals in such fashion that the error due to curve fitting never exceeds $0.1 \%$ : A more detailed discussion of the free energy calculation appears in a previous paper. ${ }^{16}$

All calculations were performed on an IBM $360 / 91$ computer. Relative humidities of $50 \%, 200 \%$, and $300 \%$ were chosen since the first is representative of atmospheric conditions and the last two are representative of conditions used in our experiments. Calculations were made using a range of $\mathrm{H}_{2} \mathrm{SO}_{4}$ vapor activities $a_{2}$ for each relative humidity such that nucleation rates of $\sim 1 \mathrm{drop} / \mathrm{cm}^{3} \mathrm{sec}$ were obtained. The nucleation rate $J$ was computed using Eq. (18). The variation of $\log J$ as a function of $a_{2}$ is presented in Figs. 6-8. We have included with each figure values of $N_{a}$, the total number of $\mathrm{H}_{2} \mathrm{SO}_{4}$ molecules per $\mathrm{cm}^{3}$. Notice that for each plot the limits of summation used in Eqs. (16) and (18) are given. These equations require that one perform a double sum whose exact upper limits are somewhat arbitrary. For a single-component system, ${ }^{26}$ the limit is generally taken far enough beyond the free energy maximum so that the transition from one cluster to the next larger can be considered irreversible. By analogy, then, for a two-component system after the drops are sufficiently far past the saddle point, they can be considered to grow irreversibly. Thus, how far beyond the saddle point the sums are truncated is of interest and will be discussed in more detail in the following section.

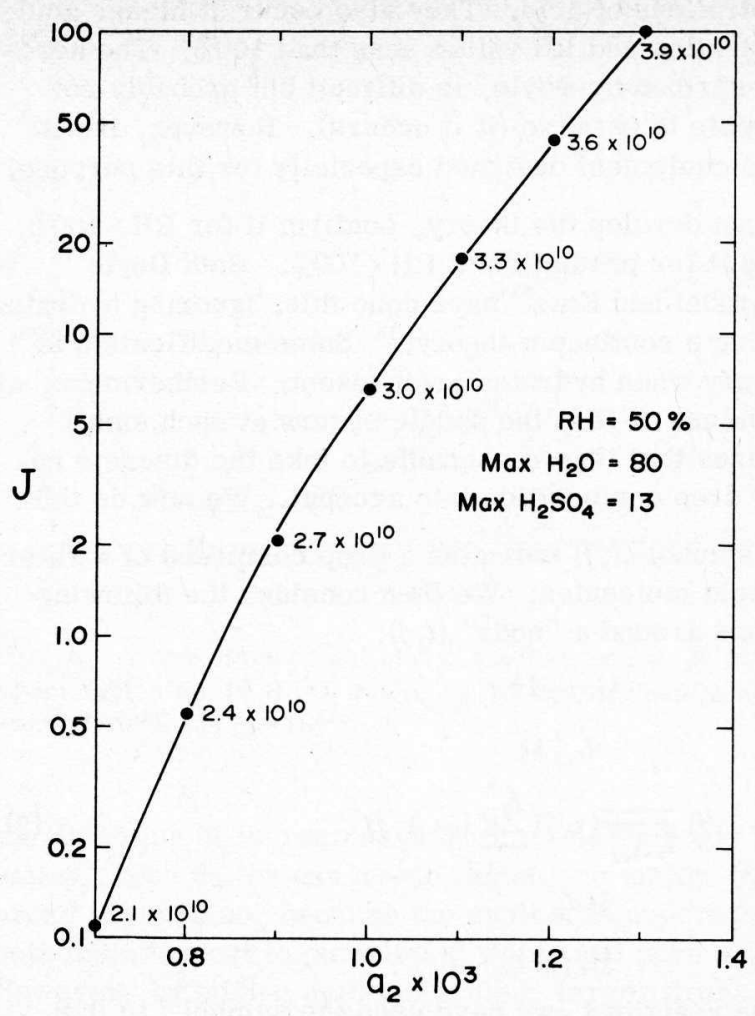

FIG. 6. A plot of the logarithm of the rate of nucleation per $\mathrm{cm}^{3}$ per second $J$ against the activity $a_{2}$ of the $\mathrm{H}_{2} \mathrm{SO}_{4}$ vapor, $25^{\circ} \mathrm{C}$ with $\mathrm{RH}=50 \%$. $N_{a}$, the total number of $\mathrm{H}_{2} \mathrm{SO}_{4}$ molecules in the vapor, is given for various activities. $\mathrm{Max} \mathrm{H}_{2} \mathrm{SO}_{4}$ and Max $\mathrm{H}_{2} \mathrm{O}$ are the upper limits of summation in Eqs. (18) and (16), respectively.

\section{DISCUSSION}

Since most of the $\mathrm{H}_{2} \mathrm{SO}_{4}$ molecules in a $\mathrm{H}_{2} \mathrm{O}-\mathrm{H}_{2} \mathrm{SO}_{4}$ vapor mixture are hydrated, ${ }^{16}$ it is important to realiz the effect hydration has upon the nucleation rate. This effect is twofold. First, the presence of hydrates tends to increase the nucleation rate since fewer interactions between $\mathrm{H}_{2} \mathrm{SO}_{4}$ and $\mathrm{H}_{2} \mathrm{O}$ molecules are required to produce a critical cluster. Each growing cluster, when acquiring a hydrate, adds not just one $\mathrm{H}_{2} \mathrm{SO}_{4}$ molecule, but a number of $\mathrm{H}_{2} \mathrm{O}$ molecules at the same time. This effect is of kinetic origin and tends to increase the nucleation rate. The second effect is of a thermodynamic origin and acts to decrease the rate. The presence of hydrates has a stabilizing influence on the vapor. It is in a sense, "buffered" by the hydrates. If one tries to increase the partial pressure of free $\mathrm{H}_{2} \mathrm{SO}_{4}$, most of th slack is taken up through formation of more hydrates, and the partial pressure or activity $a_{2}$ of the free $\mathrm{H}_{2} \mathrm{SO}_{4}$ is increased only slightly. The thermodynamic factor far outweighs the kinetic, and the overall effect of hydrate formation is to reduce the rate of nucleation.

Mirabel and Katz have calculated the nucleation rate for a $\mathrm{H}_{2} \mathrm{O}-\mathrm{H}_{2} \mathrm{SO}_{4}$ vapor mixture, ignoring hydrates and using a continuum theory. ${ }^{19}$ For a relative humidity of $50 \%$, they find a partial pressure of $3.07 \times 10^{-7} \mathrm{~mm}$ of $\mathrm{H}_{2} \mathrm{SO}_{4}$ is necessary for a nucleation rate of $1 \mathrm{drop} / \mathrm{cm}^{3}$ sec. This partial pressure corresponds to $9.80 \times 10^{9}$ molecules of $\mathrm{H}_{2} \mathrm{SO}_{4}$ per $\mathrm{cm}^{3}$. Using Eq. (18), which 


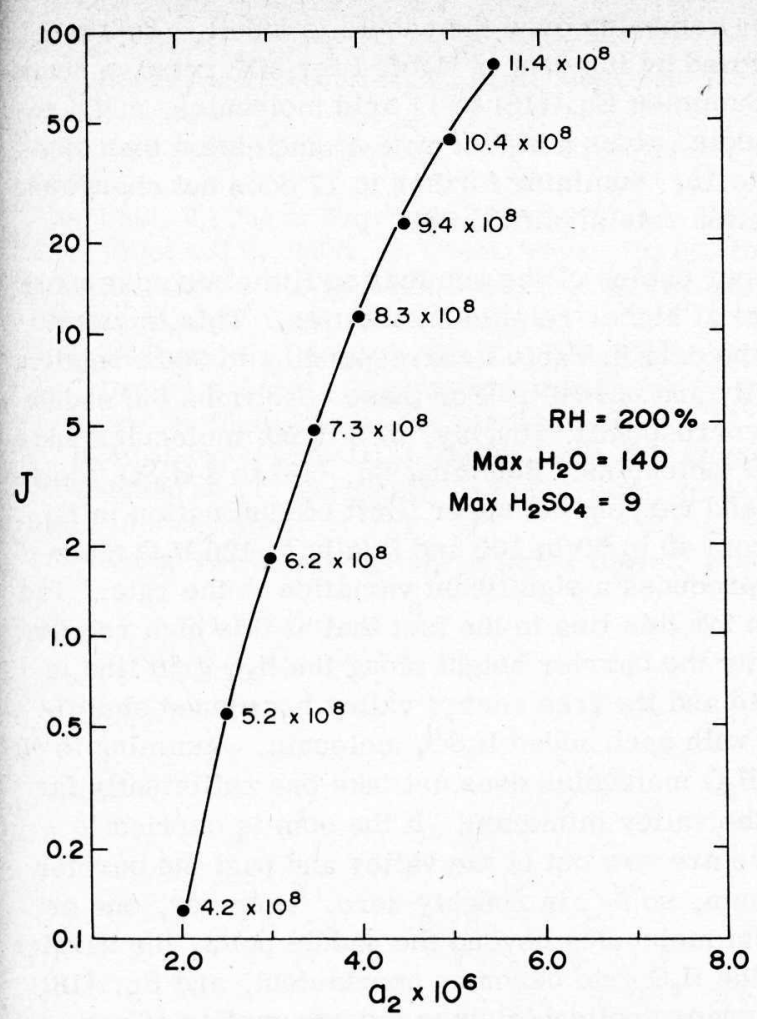

FIG. 7. A plot of the logarithm of the rate of nucleation per $\mathrm{cm}^{3}$ per second $J$ against the activity $a_{2}$ of the $\mathrm{H}_{2} \mathrm{SO}_{4}$ vapor at $25^{\circ} \mathrm{C}$ with $\mathrm{RH}=200 \%$. $N_{a}$, the total number of $\mathrm{H}_{2} \mathrm{SO}_{4}$ molecules in the vapor, is given for various activities. $\mathrm{Max} \mathrm{H}_{2} \mathrm{SO}_{4}$ and Max $\mathrm{H}_{2} \mathrm{O}$ are the upper limits of summation in Eqs. (18) and (16), respectively.

allows for hydrates and treats the cluster growth discretely, the partial pressure of unhydrated $\mathrm{H}_{2} \mathrm{SO}_{4}$ required for a unit nucleation rate at the same relative humidity is $3.02 \times 10^{-7} \mathrm{~mm}$. Because of the formation of hydrates, the total concentration of $\mathrm{H}_{2} \mathrm{SO}_{4}$ molecules in the vapor phase, whether hydrated or not, cannot be computed directly from this partial pressure. Nevertheless, this number $N_{a}$ is derivable by the methods in Ref. 16 and corresponds to $2.52 \times 10^{10}$ molecules $/ \mathrm{cm}^{3}$. This higher total concentration of $\mathrm{H}_{2} \mathrm{SO}_{4}$ is due largely to the stabilizing influence of hydration. The effect of the discrete summation in Eq. (18) is expected to be most significant for large relative humidities (e.g., $>300 \%$ ) when the critical cluster contains only a few molecules. Even though the total concentration of $\mathrm{H}_{2} \mathrm{SO}_{4}$ required when using Eq. (18) is approximately 2.6 times greater than that required by the continuum theory, it is significant that both concentrations are in the range which atmospheric $\mathrm{H}_{2} \mathrm{SO}_{4}$ concentrations may attain. ${ }^{1}$

The expression for the nucleation rate in Eq. (18) displays an extremely sharp dependence upon $\mathrm{H}_{2} \mathrm{SO}_{4}$ concentration. In Fig. 6, which corresponds to a relative humidity of $50 \%$, increasing $a_{2}$ from $8 \times 10^{-4}$ to $9 \times 10^{-4}$ (about $~ 11 \%$ ) increases the nucleation rate from 0.55 to $2.07 \mathrm{drops} / \mathrm{cm}^{3} \mathrm{sec}$ (an increase in rate of about $280 \%$ ).

If we consider Fig. 8, which corresponds to a relative humidity of $300 \%$, we see that a rate of 1 drop $/ \mathrm{cm}^{3} \mathrm{sec}$ is achieved at an $a_{2}$ of about $9.00 \times 10^{-8}$. This corresponds to a total vapor phase concentration of acid molecules (hydrated and free) of $\sim 4.3 \times 10^{7}$ molecules $/ \mathrm{cm}^{3}$, which represents, at $1 \mathrm{~atm}$ total pressure, $\sim 2$

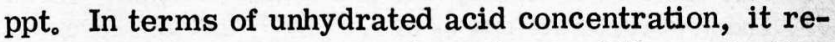
presents $\sim 0.04 \mathrm{ppt}$. The dependence of the nucleation rate on activity is still very sharp. A $25 \%$ change in $a_{2}$, in the neighborhood of a nucleation rate of 1 drop/ $\mathrm{cm}^{3} \mathrm{sec}$, produces roughly a $130 \%$ change in the rate.

As we have indicated, when performing the summations indicated in Eqs. (16) and (18), the choice of the upper limits is somewhat arbitrary. The summation in Eq. (16), along the grid lines, parallel to the water axis on the free energy surface, is usually carried out to, or slightly beyond, the free energy maximum for each grid line. This is not possible in every case, however, due to insufficient thermodynamic data. The chemical potentials required to compute the reversible work of formation and ultimately the nucleation rate have only been tabulated for solutions with at least 8.9 $w t \% \mathrm{H}_{2} \mathrm{SO}_{4}$. Those portions of the free energy surface with acid/water ratios less than about $\frac{1}{56}$ cannot be accurately calculated. If the barrier maximum along any water grid line corresponds to a cluster composition less than $8.9 \mathrm{wt} \% \mathrm{H}_{2} \mathrm{SO}_{4}$, Eq. (16) cannot be summed to the maximum. The effect of varying this upper limit of summation has been examined, and the results are given in Table $\mathrm{I}$.

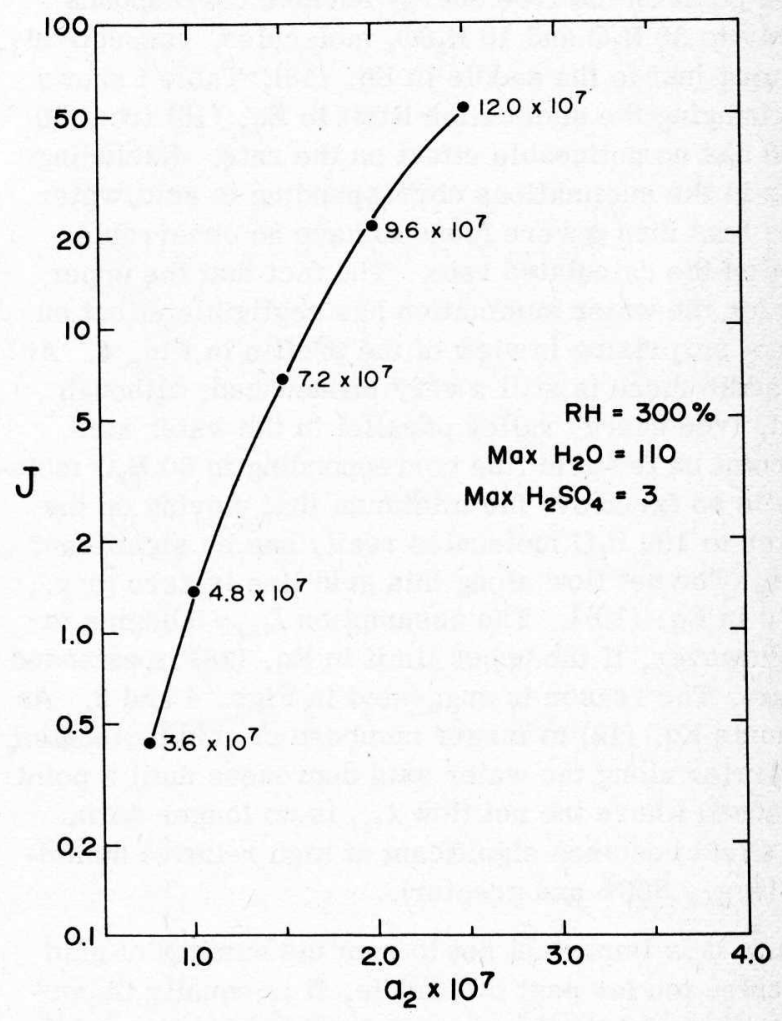

FIG. 8. A plot of the logarithm of the rate of nucleation per $\mathrm{cm}^{3}$ per second $J$ against the activity $a_{2}$ of the $\mathrm{H}_{2} \mathrm{SO}_{4}$ vapor at $25^{\circ} \mathrm{C}$ with $\mathrm{RH}=300 \%$. $N_{a}$, the total number of $\mathrm{H}_{2} \mathrm{SO}_{4}$ molecules in the vaopr, is given for various activities. $\mathrm{Max} \mathrm{H}_{2} \mathrm{SO}_{4}$ and Max $\mathrm{H}_{2} \mathrm{O}$ are the upper limits of summation in Eqs. (18) and (16), respectively. 
TABLE I. The change in rate of nucleation $J$ in number of drops $/ \mathrm{cm}^{3}$ sec for various values of $\mathrm{Max} \mathrm{H}_{2} \mathrm{O}$ and $\mathrm{Max} \mathrm{H}_{2} \mathrm{SO}_{4}$, the upper limits of Eqs. (16) and (18), respectively. The values of $J$ are calculated at $25^{\circ} \mathrm{C}$ for three different free energy surfaces. Surface A corresponds to a relative humidity RH of $50 \%$, and acid vapor activity $a_{2}$ of $1.0 \times 10^{-3}$, and an approximate saddle point composition of $30 \mathrm{H}_{2} \mathrm{O}$ and $10 \mathrm{H}_{2} \mathrm{SO}_{4}$ molecules, respectively. Surface B corresponds to $\mathrm{RH}=200 \%, a_{2}$ $=5.0 \times 10^{-6}$, and an approximate saddle point composition of $29 \mathrm{H}_{2} \mathrm{O}$ and $5 \mathrm{H}_{2} \mathrm{SO}_{4}$ molecules, respectively. Surface C corresponds to $\mathrm{RH}=300 \%, a_{2}=1.0 \times 10^{-7}$, and an approximate saddle point composition of $24 \mathrm{H}_{2} \mathrm{O}$ and $3 \mathrm{H}_{2} \mathrm{SO}_{4}$ molecules, respectively.

\begin{tabular}{lcll}
\hline \hline $\begin{array}{l}\text { Free energy } \\
\text { surface }\end{array}$ & $\begin{array}{l}\mathrm{Max} \mathrm{H}_{2} \mathrm{O} \\
\text { (molecules) }\end{array}$ & $\begin{array}{l}\mathrm{Max} \mathrm{H}_{2} \mathrm{SO}_{4} \\
\text { (molecules) }\end{array}$ & $\begin{array}{l}\text { J } \\
\text { (drops } / \mathrm{cm}^{3} \mathrm{sec} \text { ) }\end{array}$ \\
\hline \multirow{4}{*}{ A } & 63 & 10 & 4.4 \\
& 120 & 10 & 4.4 \\
& 120 & 13 & 3.1 \\
& 120 & 20 & 3.0 \\
$\mathrm{~B}$ & 63 & 6 & 18.7 \\
& 120 & 6 & 18.9 \\
& 240 & 17 & 18.3 \\
& 120 & 12 & 18.2 \\
C & 40 & 3 & 0.39 \\
& 63 & 3 & 0.49 \\
& 73 & 3 & 0.50 \\
\hline \hline
\end{tabular}

For a relative humidity of $50 \%$ and an $a_{2}$ of $10^{-3}$, the saddle point on the free energy surface corresponds roughly to $30 \mathrm{H}_{2} \mathrm{O}$ and $10 \mathrm{H}_{2} \mathrm{SO}_{4}$ molecules, respectively. Summing just to the saddle in Eq. (18), Table I shows that changing the summation limit in Eq. (16) from 80 to 100 has no noticeable effect on the rate. Excluding terms in the summations corresponding to acid/water ratios less than $\frac{1}{56}$ were found to have no observable effect on the calculated rate. The fact that the upper limit for the water summation has negligible effect on $J$ is not surprising in view of the profile in Fig. 4. At the saddle there is still a very pronounced, although broad, free energy valley parallel to the water axis. The point on the grid line corresponding to $80 \mathrm{H}_{2} \mathrm{O}$ molecules is so far above the minimum that moving up the barrier to $100 \mathrm{H}_{2} \mathrm{O}$ molecules really has no significant effect. The net flow along this grid line is zero [e.g., $I_{i, j}=0$ in Eq. (10) ]. The assumption $I_{i, j}=0$ begins to fail, however, if the upper limit in Eq. (18) is extended too far. The reason is suggested in Figs. 4 and 5. As one sums Eq. (18) to larger numbers of acid molecules, the barrier along the water axis decreases until a point is reached where the net flow $I_{i, j}$ is no longer zero. This effect becomes significant at high relative humidities (e.g., 300\% and greater).

While it is important not to sum the number of acid molecules too far past the saddle, it is equally important not to truncate the sum too quickly. At the saddle point or slightly beyond, the probability of a cluster returning to a presaddle composition is considerably greater than at a point much further from the saddle. It is necessary, then, to sum over the number of acid molecules in Eq. (18) far enough so that the chance of a cluster returning over the saddle is small. This is illustrated by the data in Table I for $50 \%$ relative humid ity. Summing Eq. (18) to 11 acid molecules, e.g., to the saddle, gives a higher rate of nucleation than summing to 15 ; summing further to 17 does not change the nucleation rate significantly.

Proper choice of the summation limit becomes more critical at higher relative humidities. This is clear from the data in Table I corresponding to $300 \%$ relative humidity and $a_{2}=10^{-7}$. For these conditions the saddle point corresponds, roughly, to $3 \mathrm{H}_{2} \mathrm{SO}_{4}$ molecules and $24 \mathrm{H}_{2} \mathrm{O}$ molecules. Summing Eq. (18) to $3 \mathrm{H}_{2} \mathrm{SO}_{4}$ molecules and varying the upper limit of summation in Eq. (16) from 40 to 60 to 100 and finally to $120 \mathrm{H}_{2} \mathrm{O}$ molecules produces a significant variation in the rate. The reason for this lies in the fact that at this high relative humidity the barrier height along the $\mathrm{H}_{2} \mathrm{O}$ grid line is lowered and the free energy valley broadened significantly with each added $\mathrm{H}_{2} \mathrm{SO}_{4}$ molecule. Summing to 40 or $60 \mathrm{H}_{2} \mathrm{O}$ molecules does not take one sufficiently far from the valley minimum. If the sum is carried to 120 , we are now out of the valley and past the barrier maximum, so $I_{i, j}$ is roughly zero. However, one or two acid molecules beyond the saddle point, the barrier along the $\mathrm{H}_{2} \mathrm{O}$ grid becomes nonexistent, and Eq. (18) is no longer applicable since the assumption of zero net flow along this direction, $I_{i, j}=0$, is invalid. For this reason, at high relative humidities (e.g., $300 \%$ or greater) we have truncated the sum in Eq. (18) at the saddle point. However, this somewhat arbitrary convention must lead to a result of uncertain accuracy, and a proper theory would, instead, deal with the steady state condition in which the assumption $I_{i, j}=0$ is replaced by

$$
I_{i-1, j}+J_{i, j-1}=I_{i, j}+J_{i, j}
$$

for each node $(i, j)$ in Eq. (2).

Note added in proof: After submitting this paper to the Journal of Chemical Physics two publications on $\mathrm{H}_{2} \mathrm{SO}_{4}-\mathrm{H}_{2} \mathrm{O}$ nucleation were brought to our attention. ${ }^{27}$

*This research was supported under NSF Grant Nos. GP$28722 \mathrm{X}$ and $40525 \mathrm{X}$.

${ }^{1} \mathrm{~J}$. Bricard, M. Cabane, G. Madelaine, and D. Vigla, in Aerosols and Atmospheric Chemistry, edited by G. Hidy (Academic, New York, 1972), p. 27.

${ }^{2}$ T. N. Rao, S.S. Collier, and J.C. Calvert, J. Chem. Soc. 91, 1609 (1969).

${ }^{3}$ E. R. Gerhard and H. F. Johnstone, Ind. Eng. Chem. 47, 972 (1955).

${ }^{4}$ H. W. Sidebottom, C. C. Badcock, G. E. Jackson et al., Environ. Sci. Technol. 6, 72 (1972).

${ }^{5} \mathrm{~K}$. Westberg and N. Cohen, "The Chemical Kinetics of Photochemical Smog as Analyzed by Computer, " AIR-70 (8107)-1, The Aerospace Corp., El Segundo, CA, December 1969.

${ }^{6}$ T. A. Hecht, J.H. Seinfeld, and M. C. Dodge, Environ. Sci. Technol. 8, 327 (1974).

${ }^{7} \mathrm{C} . \mathrm{W}$. Gear, Numerical Initial Value Problems in Ordinary Differential Equations, (Prentice Hall, New York, 1971).

${ }^{8}$ D. Golomb, R.E. Good, A. B. Bailey et al., J. Chem. Phys. 57, 3844 (1972).

${ }^{9}$ G. D. Stein and J. A. Armstrong, J. Chem. Phys. 58, 1999 (1973).

${ }^{10}$ L. B. Allen and J. L. Kassner, Jr., J. Colloid Interface Sci. 
30, 81 (1969).

${ }^{11}$ J. G. Hudson and P. Squires, J. Appl. Meteorol. 12, 175 (1973).

${ }^{12}$ J. L. Katz and B. J. Ostermier, J. Chem. Phys. 47, 478 (1967).

${ }^{13}$ J. L. Katz, J. Chem. Phys. 52, 4733 (1970).

${ }^{14}$ R. H. Heist and H. Reiss, J. Chem. Phys. 59. 665 (1973).

${ }^{15} \mathrm{~J}$. P. Hirth and G. M. Pound, Condensation and Evaporation (Pergamon, New York, 1963), Chap. B.

${ }^{16}$ R. H. Heist and H. Reiss, J. Chem. Phys. (to be published). ${ }^{17}$ G. J. Doyle, J. Chem. Phys. 35, 795 (1961).

${ }^{18} \mathrm{H}$. Reiss, J. Chem. Phys. 18, 840 (1950).

${ }^{19} \mathrm{P}$. Mirabel and J. L. Katz, J. Chem. Phys. 60, 1138 (1974).

${ }^{20}$ J. I. Gmitro and T. Vermeulen, AIChE J. (Am. Inst. Chem. Eng.) 10, 740 (1964).

${ }^{21}$ L. B. Loeb, The Kinetic Thəory of Gases (Dover, New York,
1961), Chap. 3.

${ }^{22} \mathrm{~J}$. Frenkel, The Kinetic Theory of Liquids (Dover, New York, 1955), p. 392.

${ }^{23}$ R. P. Andres, in Nucleation, edited by A. C. Zettlemayer (Decker, New York, 1969), Chap. 2.

${ }^{24}$ W. F. Giauque, E. W. Hornung, J. E. Kunzler, and T. R. Rubin, J. Chem. Soc. 82, 62 (1960).

${ }^{25}$ Chemical Engineers Handbook, 4th ed. (McGraw-Hill; New York, 1963), Table 3-120.

${ }^{26}$ L. Sabinina and L. Terpugow, Z. Phys. Chem. A 173, 237 (1935).

${ }^{27}$ (a) C. S. Kiang and D. Stauffer, Faraday Symposia of The Chemical Society, No. 7 (The University Press, Aberdeen, U. K., 1973), p. 26; (b) C. S. Kiang, D. Stauffer, V. A. Mohnen et al., Atmospheric Environment, Vol. 7 (Pergamon, London, 1973), p. 1279. 